\title{
14-3-3 proteins —an update
}

\author{
Paulette MHAWECH* \\ Department of Pathology and Laboratory Medicine at Roswell Park Cancer Institute,Elm and Carlton Streets. Buffalo, New \\ York14263, USA
}

\begin{abstract}
14-3-3 is a highly conserved acidic protein family, composed of seven isoforms in mammals. 14-3-3 protein can interact with over 200 target proteins by phosphoserine-dependent and phosphoserine-independent manners. Little is known about the consequences of these interactions, and thus are the subjects of ongoing studies. 14-3-3 controls cell cycle, cell growth, differentiation, survival, apoptosis, migration and spreading. Recent studies have revealed new mechanisms and new functions of 14-3-3, giving us more insights on this fascinating and complex family of proteins. Of all the seven isoforms, 14-3-3 $\sigma$ seems to be directly involved in human cancer. 14-3-3 $\sigma$ itself is subject to regulation by 533 upon DNA damage and by epigenetic deregulation. Gene silencing of 14-3-3 $\sigma$ by CpG methylation has been found in many human cancer types. This suggests that therapy-targeting 14-3-3 $\sigma$ may be beneficial for future cancer treatment.
\end{abstract}

Keywords: 14-3-3 function, 14-3-36, CpG methylation, target therapy.

\section{INTRODUCTION}

Gene inactivation leading to cancer can be due to epigenetic causes. One epigenetic event involves changes in chromatin conformation due to histone modification by acetylation and deacetylation. Another has been associated with transcriptional silencing, due to methylation of $\mathrm{CpG}$ islands around the gene promoter. Gene silencing through promoter hypermethalytion has been the subject of a large number of studies and has gained interest for numerous reasons. Methylation occurs early in cancer, and therefore it can be a useful tool to detect recurrences or relapses. In addition, gene methylation can be detected in body fluids and urine. Finally, reversal of hypermethylation can be achieved by administration of new therapeutic compounds including the metyltransferase inhibitor 5-Azacytidine, and histone deacetylase inhibitors [1-2]. A growing list of tumor suppressor genes silenced by DNA hypermethylation of the promoter are described in various cancer types, including fragile histidine triad

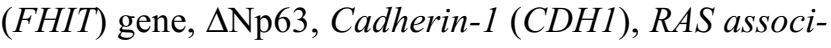

*Correspondence: Paulette MHAWECH

Phn: +01-716-845-3204

Fax: +01-716-845-3427

E-mail: pmhawech1@yahoo.com ated domain family (RASSF1A), Cadherin 13 (CDH13), secreted frizzled related protein-1 (sFRP1), retinoic acid beta $(R A R \mathrm{~b})$, p16 and death associated kinase (DAPK), and 14-3-3 $\sigma$ genes [3]. 14-3-3 $\sigma$ will be the topic of our review.

$14-3-3 \sigma$ belongs to the $14-3-3$ protein family, which is a class of highly conserved proteins involved in regulating signal transduction pathways, apoptosis, adhesion, cellular proliferation, differentiation and survival. Among all 14-33 proteins, $14-3-3 \sigma$ is the isoform most directly linked to cancer [4]. There are several lines of evidence indicating that $14-3-3 \sigma$ acts as a tumor suppressor gene and that its inactivation is crucial in tumorigenesis. In this review, we will summarize the role of 14-3-3 protein in controlling cell cycle, apoptosis and adhesion. Emphasis will be given to the most recent research work elucidating its function and its mechanism. Secondly, we will discuss the potential

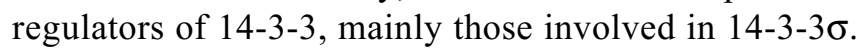

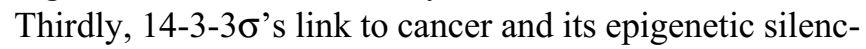
ing will be described. Ultimately, we will conclude by discussing the potential use of specific targeted therapies toward $14-3-3 \sigma$ for patients with cancer.

\section{4-3-3 PROTEINS, AN OVERVIEW}

The discovery of 14-3-3 proteins goes back to the work 
of Moore and Pretz in 1968, when they found 14-3-3 in brain tissue. The peculiar name, 14-3-3, was given to this family of protein due to their characteristic migration pattern on scratch-gel electrophoresis [5]. 14-3-3 proteins belong to a family consisting of highly conserved acidic proteins, with molecular weights of $25-30 \mathrm{kD}$. It is composed of at least seven mammalian isoforms, which are found in all eukaryocytic cells. 14-3-3 acts as an adaptor or "chaperone molecule", which is able to move freely from cytoplasm to nucleus and vise-versa [6]. 14-3-3 proteins are mainly cytoplasmic molecules. It can form homodimers or heterodimers, and interact with various cellular proteins. They are phosphoserine-binding proteins that bind to the consensus motifs RSXpSXP and RXY/ FXpSXP. These consensus motifs are present in almost all of the 14-3-3 binding proteins [7]. Over hundred small molecules interact with 14-3-3 in a phosphorylation-dependent manner. These proteins include protein kinases (murine leukemia viral oncogene homologue - RAF1, MEK kinase, PI3 kinase, and Grb10), receptor proteins (insulin-like growth factor 1 and glucocorticoid receptors), enzymes (serotonin $N$-acetyltransferase, tyrosine and tryptophane hydroxylase), structural and cytoskeletal proteins (vimentins, and keratins), scaffolding molecules (calmodulin), proteins involved in cell cycle control ( $c d c 25$, $p 53, p 27$, and wee1) and proteins involved in transcriptional control (histone acetyltransferase, and TATA box binding proteins), and proteins involved in apoptosis (BAD) $[7,8]$. However, a few proteins interact with 14-3-3 in a phosphorylation-independent manner such as (Bax). Recently, using direct proteomic analysis, researchers have identified a large number of polypeptides $(>200)$ that can associate with 14-3-3 proteins. These polypeptides are involved in numerous cell functions. These functions include fatty acid synthesis, reductive metabolism, iron and other metabolisms, DNA/ chromatin interactions including transcription factors, RNA binding, protein synthesis, protein folding and processing, proteolysis, protease inhibitors, ubiquitin metabolism, cellular signaling and apoptosis, actin dynamics, cellular trafficking and tansporters, signaling kinases, cell division, nuclear proteins, oncogenic signaling, and cytoskeletal proteins $[9,10]$. An study demonstrated that some of the 14-3-3 binding proteins are involved in the regulation of the cytoskeleton, GTPase function, membrane signaling, and cell fate determination [11]. It is difficult to list the numerous 14-3-3-interacting proteins here. The important consequences of these interactions include alterations of enzymatic activity, inhibition or promotion of protein interactions, and enhanced pos-translational modifications such as phosphorylation. However, many other consequences are still unknown. So far, the most common func- tion of 14-3-3 is sequestration of proteins in the cytoplasm, leading to inhibition of their function [12].

\section{4-3-3 in cell growth, survival and differentiation}

14-3-3 regulates cell growth, survival and differentiation. These tasks are achieved through various mechanisms. 14-3-3 regulates cell growth through its interactions with Raf-1 in Raf-1/ERK, the extracellular signal-regulated kinase (also known as the mitogen activated protein, MAP) pathway. The MAPK signaling cascade control cell growth, differentiation and survival, involving many substrates and numerous steps. Growth factors, hormones and mitogens stimulate the activity of extracellular signalregulated protein kinases ERK1 and ERK2. ERK1/ERK2 are activated by the mitogen-activated protein kinase kinases MAPKK (or ERK activator kinases), MEK1 and MEK2, which are activated by Raf-1 (MAP3K). For Raf-1 activation, a recruitment to the plasma membrane is required, where Ras is localized and functions as a stimulator of Raf-1 activity. Once MEK1 and MEK2 are activated, they will activate MAPK. Down in the cascade, both MEK1/2 and MAPK activate latent transcription factors and change patterns of gene expression [13]. The regulation of Raf-1 by 14-3-3 protein is a well-known phenomenone, but the exact mechanism is very complex and still the subject of ongoing research. However, the most recent data start to unfold the story [14, 15]. All of the Raf isoforms contain two binding sites for 14-3-3 proteins. In addition, 14-3-3 has 2 binding sites on the same protein, one of which is a dominant site or a "gate keeper" site [16]. In unstimulated cells, the dominant site is phosphorylated, whereas the second site is not. This Raf-1 is unable to promote stable Raf/14-3-3 interactions. Thus, each 14-3-3 dimer is only bound to its target protein through one of its two binding motifs. When the second site in Raf- 1 is also phosphorylated, it will bind rapidly to the target protein due to the high local concentration induced by proximity. Complying with this model, a study showed that the first motif is located on $\mathrm{Ser}^{621}$, a regulatory region important for Raf-1 activation. The second motif is located on $\mathrm{Ser}^{259}$, a catalytic region important for Raf-1 suppression [14]. In unstimulated cells, Raf-1 is not phosphorylated on $\operatorname{Ser}^{259}$, and 14-3-3 is unable to bind to the Nterminus of Raf- 1 to allow the recruitment of Raf- 1 to the plasma membrane for activation. When both sites are phosphorylated, 14-3-3 will bind to the N-terminus of Raf-1 to introduce a conformational change in Raf-1. 143-3 itself however only undergoes a slight conformational change during this process. As a consequence, 14-3-3 sequesters Raf-1, blocking its recruitment to the plasma membrane [15]. This in turn, inhibits Ras signaling to the MAP kinase pathway. Another mechanism by which 14- 
3-3 protein regulates cell growth and survival is by regulation of mitogen-activated kinase-1 (BMK1). BMK1 is another member of the MAPK family, which promotes cell proliferation, and inhibits apoptosis [17]. The regulation of BMK1 is not well understood. MEK5 is the upstream kinase that activates BMK1 via phosphorylation. This activation leads to the phosphorylation and subsequent activation of the transcription factor MEF2C [18]. Recently, the isoform 14-3-3 $\beta$ was implicated in BMK1 regulation. It appears that phosphorylation of BMK1 on $\operatorname{ser}^{486}$ within its $\mathrm{C}$ terminus is required for its binding to $14-3-3 \beta$. Furthermore, the binding of $14-3-3 \beta$ to BMK1 inhibits the phosphorylation of BMK1 and subsequently blocks the activation of MEF2C. Additionally, another mode other than phosphorylation has been suggested [19]. It has been shown that by interacting with $\operatorname{ser}^{486}$, a region located within the BMK1-MEF2C interaction site, 14-3-3 may competitively inhibit the binding of MEF2C to BMK1. Therefore, 14-3-3 inhibits BMK1 from activating its transcription factor substrates.

Recent studies showed that 14-3-3 controls cell proliferation by binding to $\mathrm{p} 27$. p27 is a cyclin-dependent kinase inhibitor, which upon migration to the nucleus inhibits cyclin dependent kinase activity and blocks cell cycle progression. Since cyclin-dependent kinases are nuclear proteins, localization of p27 in the nucleus is vital for its ability to inhibit these kinases $[20,21]$. The phosphatidylinositol-3 kinase (PI3K)/Akt pathway regulates cell proliferation, survival and motility, and its inappropriate activation has been implicated in carcinogenesis [21]. Akt phosphorylates p27 on $\mathrm{Ser}^{10}$, $\mathrm{Thr}^{157}$, and $\mathrm{Thr}^{198}$. Phosphorylation of $\mathrm{p} 27$ on $\mathrm{Th}^{157}$ causes its association with 143-3. 14-3-3 sequesters p27 in the cytoplasm, and thus, inhibits its nuclear function [22]. The end result is activation of cyclin CDK complex activity and cell cycle progression.

Another mechanism by which 14-3-3 controls cell growth is through its regulation of tuberous sclerosis genes. TSC1 encodes hamartin, and TSC2 encodes tuberin. Both genes are considered to be tumor suppressor genes. Inactivation by point mutations in TSC1 or TSC2 genes have been reported in patients with tuberous sclerosis, an autosomal-dominant condition characterized by the development of hamartomas in many organs. The TSC1/TSC2 complex plays an important role in inhibiting cell growth and in control of cell size. Both genes are involved in controlling the transition from the $\mathrm{G}_{1}$ phase to $\mathrm{S}$ phase [23]. Furthermore, overexpression of TSC1 gene triggers an increase in cyclin dependent kinase inhibitor, p27 expression [24]. Therefore, TSC1 could be involved in cell cycle control through the P27 cell cycle regulator. There is line of evidence showing the involvement of 14-3-3 in cell cycle regulation via TSC1/TSC2 complex. Using proteomics analysis, Hengstchlager et al showed that the cellular levels of four 14-3-3 isoforms $(\gamma, \varepsilon, \zeta$, and $\sigma)$ were up regulated by the TSC1/TSC2 complex [25]. This suggests that members of the 14-3-3 family are involved in cell cycle regulation via TSC1/TSC2. Furthermore, recent studies showed that TSC2, but not TSC1, is able to interact with 14-3-3 [26]. This interaction is phosphorylation-dependent, requiring TSC2 phosphorylation on Ser ${ }^{1210}$ by an unknown kinase. The association of 14-3-3 to TSC2 leads to functional inhibition of TSC2 [27].

\section{4-3-3 in cell cycle regulation and apoptosis}

14-3-3 plays a major role in cell cycle regulation. The association of 14-3-3 with its target proteins affects cell cycle progression. This occurs through different mechanisms and may occur by affecting protein localization or by modification of their enzymatic activity. Cdc25C is a member of the Cdc25 family of dual protein phosphatases, which includes Cdc25A, Cdc25B, and Cdc25C. Cdc25B and $\mathrm{Cdc} 25 \mathrm{C}$ have been implicated in the activation of the CDCK1/cyclinB1 complex, which advances the cell cycle from $\mathrm{G}_{2}$ to $\mathrm{M}$ phase. Cdc25C activates the cyclin-dependent kinase $\mathrm{CDC} 2$, which drives the cells through mitosis. Overexpression of $\mathrm{Cdc} 25 \mathrm{~B}$ induces premature mitosis, more efficiently than $\mathrm{Cdc} 25 \mathrm{C}$, and leads to mitotic catastrophe [28-29]. During interphase, the 14-3-3 isoforms $\varepsilon$ and $\gamma$ bind to $\mathrm{Cdc} 25 \mathrm{c}$. This results in $\mathrm{Cdc} 25 \mathrm{C}$ sequestration in the cytoplasm, and leads to its inactivation, presumably by preventing the premature activation of CDC2. This binding requires the phosphorylation of $\mathrm{Cdc} 25 \mathrm{C}$ on $\mathrm{Ser}^{216}$ by TAK1 kinase and maybe by other unidentified kinases [30]. Furthermore, CDC2 blocks the inhibition of its own activator, insuring that it could become activated once mitosis is initiated. A similar mechanism takes place after DNA damage when the so called "checkpoint kinase" $\mathrm{CH} 1 \mathrm{~K}$ becomes activated. $\mathrm{CH} 1 \mathrm{~K}$ phosphorylates Cdc25C resulting the binding of the latter to 14-3-3 [31]. Subsequently, Cdc25C becomes sequestrated in the cytoplasm and results in cell cycle arrest in $\mathrm{G}_{2}$ phase. In contrast, $14-3-3 \sigma$ does not bind directly to Cdc25C like the other isoforms. Instead, 14-3-3 $\sigma$ affects cdc25C indirectly by inhibiting the premature chromatin condensation induced by $\mathrm{Cdc} 25 \mathrm{C}$ [30]. Finally, by the same mechanism of regulation, the 14-3-3 isoforms $\beta$ and $\varepsilon$, inhibits $C d c 25 B$ [32]. As we mentioned earlier, 14-3-3 controls the cell cycle by directly affecting wee-1 enzymatic activity. Wee-1, a tyrosine kinase, is activated by phoshorylation during interphase. The association of 14-3-3 to wee-1 phosphorylated on $\mathrm{Ser}^{642}$, enhances its activation. Activated wee-1 inhibits CDC2 phosphorylation and blocks cell cycle progression [33]. 
14-3-3 regulates apoptosis through its interactions with the two pro-apoptotic proteins Bax and BAD. Normally, Bax is located in the cytoplasm in an inactive state. Upon DNA damage, and in the absence of 14-3-3 $\sigma$, Bax translocates to the mitochondria around the centrosomes and drives the cells for rapid progression into apoptosis. However, when 14-3-3 $\sigma$ is present, 14-3-3 $\sigma$ interacts with Bax in a phosphorylation-independent manner, leading to the sequestration of Bax in the cytoplasm. This prevents the cell from entering apoptosis [34]. Recently, similar effects upon interaction of 14-3-3 $\theta$ with Bax have been reported [35]. Additionally, 14-3-3 controls apoptosis by its regulation of BAD. BAD inhibits the antiapoptotic functions of $\mathrm{Bcl} 2$ and Bclx. Following the phosphorylation of BAD by Akt, protein kinase A, and ribosomal S6 kinase-1, BAD will associate with 14-3-3. Subsequently, 14-3-3 induces conformational changes in $\mathrm{BAD}$, resulting in its dissociation from $\mathrm{Bcl} 2$ or Bclx. This, in turn blocks the pro-apoptotic effects of BAD [36]. Thus, 14-3-3 proteins play an active role in delaying and suppressing apoptosis, and in allowing time for DNA repair after cellular damage.

\section{4-3-3 in cell spreading and migration}

14-3-3 plays a role in controlling cellular spreading and migration through integrin regulation. Integrins are a family of cell-surface glycoproteins that link the extracellular matrix to the actin cytoskeleton. By regulating signal transduction across the plasma membrane, integrins are capable of controlling cellular spreading, migration, and survival [37]. 14-3-3 $\beta$ interacts with the cytoplasmic tail of $\beta 1$-integrin, and overexpression of $14-3-3 \beta$ stimulates cell spreading and migration [38]. Numerous proteins interact with 14-3-3, either by a phosphoserine-dependent or by a phosphoserine-independent manner. However, unlike these other proteins, the cytoplasmic tail of $\beta 1$-integrin does not contain sequence motifs for binding 14-3-3 in a phosphoserine-dependent or in phosphoserine-independent manners. Another mechanism must exist to allow the binding of $\beta$-integrin to $14-3-3 \beta$. A recent study showed that 14-3-3 $\beta$ contains a novel-binding site for its interaction with $\beta 1$ integrin [39]. This interaction requires residues, such as $\operatorname{Ser}^{60}$ on helix C, which is located outside of the amphipathic grooves of 14-3-3 $\beta$. Thus, the phosphorylation of $\operatorname{Ser}^{60}$ may block the interaction of $14-3-3 \beta$ with $\beta 1$-integrin cytoplasmic domain. This promotes cell spreading and migration. Additionally, 14-3-3 $\beta$ may promote cell spreading and migration by interacting with Raf-1, or p130cas, (a small protein implicated in cell spreading), or other signaling pathways involved in cell migration [40].

Another mechanism by which 14-3-3 affects cell spreading and migration is through its regulation of the
$\mathrm{Ca}^{2+} /$ calmodulin-dependent protein kinase (CaMK) pathway. Elevated intracellular calcium triggers multiple signaling pathways including the CaMK cascade, its downstream targets CaMKI, CaMKIV, and protein kinase B (PKB). CaMKI is cytosolic and regulates mRNA translation, cytoskeletal organization, and axonal growth cone motility [41]. CaMKIV is nuclear and regulates gene transcription. Moreover, CaMKI and CaMKIV have phosphorylation sites, which in the presence of elevated intracellular $\mathrm{Ca}^{2+}$, become activated through phosphorylation by CaMK kinase (CaMKK). Recently, it has been shown that PKAmediated phosphorylation of CaMKK occurs at 3 regulatory sites, $\mathrm{Ser}^{74}, \mathrm{Ser}^{108}$, and $\mathrm{Ser}^{458}$. The latter two phosphorylations lead to its inactivation. Phosphorylation of $\mathrm{Ser}^{74}$ causes CAMKK to bind to $14-3-3$, resulting in CAMKK inhibition. Secondly, this binding blocks the subsequent dephosphorylation of $\mathrm{Thr}^{108}$, resulting in maintaining CAMKK in an inactive state [42].

\section{4-3-3 $\sigma$}

$14-3-3 \sigma$ is primarily expressed in epithelial cells. It is also known as HEM-1, human epithelial marker (HEM) or as stratifin. By immunohistochemistry, 14-3-3 $\sigma$ (HEM/ startifin) was seen in both the cytoplasm and the nucleus of normal tissue. This shows once more that 14-3-3 is a dynamic protein that can shuttle in and out the nucleus as needed. Strong 14-3-3 $\sigma$ expression was observed in the keratinocytes of the skin, in urothelial epithelium, in periductal and periglandular cells of the prostate, in breast and in squamous epithelium of the exocervix. On the other hand, no 14-3-3 $\sigma$ expression was seen in the germinal cells of the testis, or ovary, or in the thyroid, liver, lymph node, or skeletal muscle. Focal sporadic expression was seen in the renal tubules, but none was seen in the glomeruli [43] (Fig. $1 \mathrm{~A}-\mathrm{C}$ ).

$14-3-3 \sigma$ seemed to be regulated by different mechanisms, which when altered contributed directly to cancer development. The major regulator of $14-3-3 \sigma$ is the tumor suppressor gene, p53. Following cellular DNA damage, p53 is activated. Subsequently, p53 either mediates a cell cycle arrest or apoptosis, ensuring the maintenance of gene stability. p53 regulates the cell cycle by inducing $G_{1} / S$ arrest which is mediated by $\mathrm{p} 21$. In addition, $\mathrm{p} 53 \mathrm{regu}-$ lates the $\mathrm{G}_{2} / \mathrm{M}$ checkpoint by inducing 14-3-3 $\sigma$ expression. Upon DNA damage, p53 becomes dephosphorylated and is able to bind the promorter region $1.8 \mathrm{~kb}$ upstream of 14-3-3 $\sigma$ transcription start site. The subsequent activation and increased expression of 14-3-3 $\sigma$ lead to the sequestration of CDK1/cyclin B1 in the cytoplasm, and thereby blocks the interaction of CDC2 with CDK1 and the entry of the cell into mitosis, allowing time for DNA repair [44-46]. Furthermore, 14-3-3 $\sigma$ may directly increase 

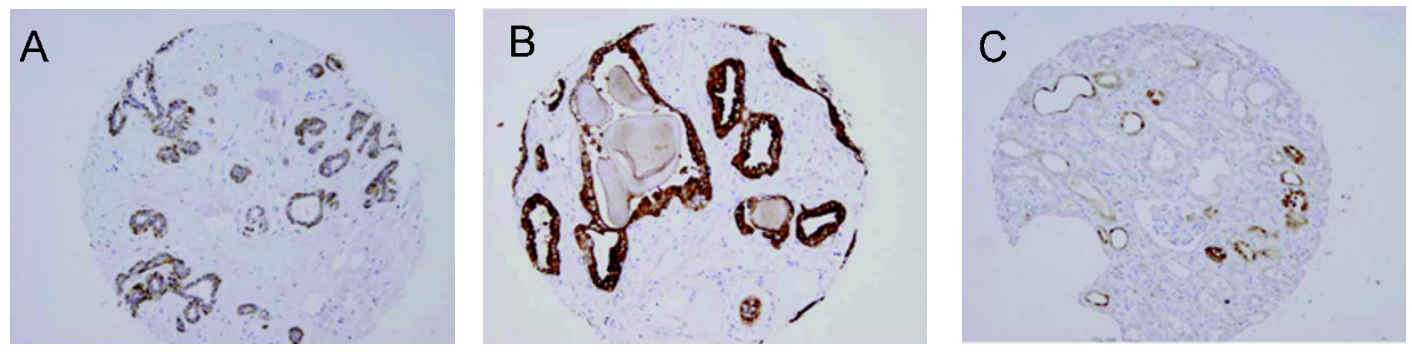

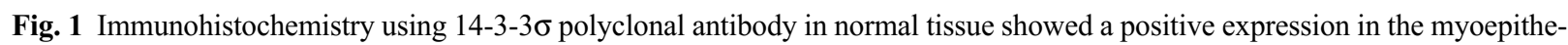
lial cells of normal breast tissue (A), in the basement membrane and epithelia cells of normal prostate (B). There is focal and sporadic expression in normal renal tubules, but not in the glomeruli (C).

the transcriptional activity of $\mathrm{p} 53$, suggesting a positive feedback loop. In cancer, mutated p53 results in a decrease in 14-3-3 $\sigma$ expression. Therefore, $14-3-3 \sigma$ will not be able to arrest the cancerous cell in the $\mathrm{G}_{2}$ phase, thus allowing the occurrence of mutations and aberrant chromosomes structures. Recently another tumor suppressor gene, $B R C A 1$, has been shown to act synergistically with p53 during DNA damage [47]. In irradiated $14-3-3 \sigma^{-/}$cells, there is increased frequency of chromosome end-end associations with loss of telomeric repeat sequences. Even without radiation-induced DNA damage, $14-3-3 \sigma^{-/}$cells have an increase frequency of genetic aberrations [48]. This genetic instability seen in 14-3-3 $\sigma$ deficient cells may contribute to tumor progression. Secondly, 14-3-3 $\sigma$ may be regulated by $\mathrm{p} 63$, a protein, which controls cell cycle arrest and /or apoptosis. $p 63$ encodes two major isoforms, $\mathrm{TA}$ (transcriptionally active) $\mathrm{p} 63$ and $\Delta \mathrm{N}$ (dominant negative) p63. When overproduced, the TAp63 isoform induces apoptosis by transactivation of $\mathrm{p} 53$. The $\Delta \mathrm{Np} 63$ suppresses both $\mathrm{p} 53$ and TAp63 transactivation in a dominant negative manner [49]. p63, in which the $\Delta$ Np63 products account for virtually all p63 protein expression, is mainly expressed in the basal/progenitor cell compartment of epithelial structures. 14-3-3 $\sigma$ is highly expressed in keratinocytes at both the mRNA and protein levels, whereas its expression is repressed in the basal/progenitor cells [50]. In the basal cells, suppression of $14-3-3 \sigma$ is mediated by $\Delta$ Np63. $\Delta$ Np63 regulates the stem-cell fate by occupying the p53- binding site on 14-3-3 $\sigma$ resulting in repression of its function. When keratinocytes become more differentiated, $\Delta \mathrm{Np} 63$ is no longer produced, the suppression of $14-3-3 \sigma$ is lifted, and $14-3-3 \sigma$ is again expressed. Thirdly, $14-3-3 \sigma$ can be regulated by estrogen-induced zinc finger protein (EFP). In breast epithelial cells, 14-3$3 \sigma$ expression seems to be post-translationally regulated through the interaction with EFP, which results in 14-3$3 \sigma$ ubiquitinylation and its rapid degradation. Furthermore, over-expression of EFP in vivo can induce tumors presumably by inducing genomic instability due to the loss of

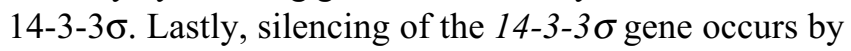
$\mathrm{CpG}$ methylation, and it is seen in various cancers

\section{4-4-3 $\sigma$ AND CANCER}

$14-3-3 \sigma$ is a tumor suppressor gene, which contributes to cancer development. Gene silencing of 14-3-3 $\sigma$, mainly by $\mathrm{CpG}$ methylation, occurs in numerous solid tumor types and even in hematologic malignancies (also see review in the same issue by Lodygin and Hermeking) [52]. There is a significant association between aberrant 14-3-3 $\sigma$ protein expression (as shown by immunohistochemistry (IHC) and $\mathrm{CpG}$ methylation detected by methylation specificPCR (MSP). 14-3-3 $\sigma$ methylation and its aberration expression are seen in preneoplastic lesions such as vulval intraepithelial neoplasia (VIN) $(60 \%)$, prostatic intraepithelial neoplasia (PIN) (95\%), ductal carcinoma in situ $(83 \%)$, atypical hyperplasia (38\%), and even in morphologically normal tissue adjacent to cancer [53-55]. Epigenetic modification of the $14-3-3 \sigma$ gene is a very early event in carcinogensis and can precede any morphologic change in tissue. Therefore, evaluation of 14-3-3 $\sigma$ methylation in urine and body fluids may be useful in monitoring recurrence in cancer patients and/or detection early disease. However, 14-3-3 $\sigma$ methylation was recently detected in normal lymphocytes, and lymphoid malignancies such as precursor B ALL, Burkitt's lymphoma, and ALL cell lines [56]. This may give false positive results when using body

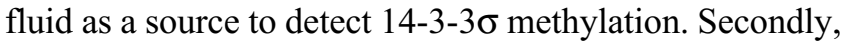
when analyzing 14-3-3 $\sigma$ methylation in human tissues for research purposes, strong inflammatory reactions accompanying epithelial tumors could give false positive results.

$14-3-3 \sigma$ downregulation, by $\mathrm{CpG}$ methylation, is detected in adenocarcinomas of breast $(96 \%)$, in squamous cell carcinoma of the vulva (60\%), in lung cancer ( $83 \%)$, in hepatocellular carcinoma (89\%), in ovarian carcinoma 

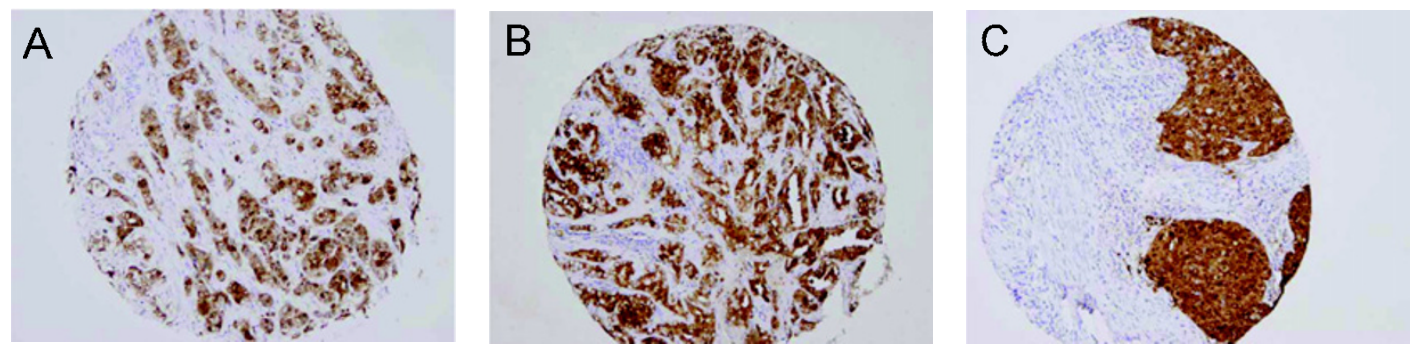

Fig. 2 There is strong 14-3-3 $\sigma$ expression in breast adenocarcinoma (A), prostate adenocarcinoma (B), and squamous cell carcinoma of the exocervix of the uterus $(\mathbf{C})$.

$(60 \%)$, in endometroid endometrial adenocarcinoma $(74 \%)$, in gastric adenocarcinoma (43\%), in basal cell carcinoma BCC (68.3\%), in squamous cell carcinoma of the bladder, in neuroendocrine tumors $(85 \%)$, and in prostate cancer (45\%) [57-63] (Fig. 2 A-C). However, 14-3-3 $\sigma$ appears to have no role in the pathogenesis of renal and testicular tumors [64]. Surprisingly, 14-3-3 $\sigma$ is highly expressed in pancreatic adenocarcinoma [65]. In lung cancer, inactivation of $14-3-3 \sigma$ by DNA methylation appears to be typespecific where it is more frequent in small cell carcinoma cell lines (57\%) than in non-small cell carcinoma cell lines (6\%) [66]. In breast cancer, using a proteomic approach, Vercoutter-Edouart et al showed that $14-3-3 \sigma$ is strongly downregulated in breast cancer in comparison to normal breast tissue, whereas, the levels of other isoforms $(\alpha, \beta$, $\delta, \zeta)$ were the same in both normal and breast cancer [67]. Therefore, 14-3-3 $\sigma$ may play an important role in breast cancer carcinogenesis. No association between p53 mutations and 14-3-3 $\sigma$ expression in human tissues was seen, suggesting that the constitutive expression of 14-3$3 \sigma$ may be dependent on other factors rather than p53 $[60,64]$. Furthermore, no association between 14-3-3 $\sigma$ downregulation and increased level of the dominant-negative transcriptional regulator $\Delta \mathrm{Np} 63$ was seen [58]. In lung cancer, one report showed that squamous cell carcinomas express $14-3-3 \sigma$ more strongly than adenocarcinomas, suggesting that this protein has a tendency to be more expressed in cells with squamous differentiation [62]. As an epithelial marker, 14-3-3 $\sigma$ expression could distinguish prostatic adenocarcinoma from urothelial carcinoma and seminoma from embryonal carcinoma [68]. This finding may help pathologists to differentiate these tumor types. However, similar to all of the immunohistochemical markers, the expression of 14-3-3 $\sigma$ should be interpreted in the context of a panel of antibodies when used for diagnostic purposes.

Why is $14-3-3 \sigma$ so unique among all of the 14-3-3 family proteins? And why are there so many isoforms? Recently, studies showed that $14-3-3 \sigma$ and the other isoforms differ in structure [69-70]. The authors showed that endogenous 14-3-3 $\sigma$ forms homodimers, while the other isoforms form homodimers and heterodimers. Secondly, 14-3-3 $\sigma$ has 3 unique amino acids Met202, Asp204, and His206. These amino acids may form a unique binding site for a ligand, which only binds to $14-3-3 \sigma$. These three unique amino acids may cause the inability of $14-3-3 \sigma$ to bind Cdc $25 \mathrm{C}$. However, all other isoforms are able to bind to $\mathrm{Cdc} 25 \mathrm{C}$. In addition, significant structural differences between the 14-3-3 isoforms have been detected and these differences seem to reside adjacent to the amphipathic groove, a region where 14-3-3 binds with numerous phsophoserine ligands. Study by van Hermet et al showed a difference in the protein distribution among the 14-3-3 isoforms [71]. They found that $14-3-3 \sigma$ is mainly localized in the cytoplasm and only low levels are present in the nucleus. On the other hand, 14-3-3 $\zeta$ was mainly present in the nucleus. In addition, $14-3-3 \sigma$ was able to shuttle in and out of the nucleus at higher rate than $14-3-3 \zeta$. Therefore, $14-3-3 \sigma$ would pass into the nucleus and back to the cytoplasm while $14-3-3 \zeta$ would pass into the nucleus and stay there. Together, these studies show that 14-3-3 proteins are not static molecules, that they sequester ligand proteins in the cytoplasm, but they actively shuttle in and out of the nucleus, and that by doing so they change the distribution of their bound-proteins. In addition, the difference in structure between 14-3-3 $\sigma$ and the other isoforms may account for their differences in substrate specificity.

\section{4-3-3 AS POTENTIAL THERAPEUTIC TARGET IN CANCER}

14-3-3 are abundant proteins and have many functions. Inhibition of 14-3-3 protein expression may prove detrimental to the cells. Alternatively, specific isoforms or specific functions of these isoforms may be able to be targeted. One isoform that could be a potential target for therapeutic agents is $14-3-3 \sigma$ [72]. However, no inhibitor of 14-3- 
$3 \sigma$ has been designed. Difopein is a competitive inhibitor of BAD binding to 14-3-3 $\sigma$. Treatment of cells with difopein might cause BAD to dissociate from 14-3-3 $\sigma$ and to bind to Bcl2. This will cause the cells to enter apoptosis. Difopein could be used in conjunction of conventional chemotherapy to trigger apoptosis. Another approach could be through phosphorylation of 14-3-3 substrates, such as Cdc25C, which leads to cell cycle progression. Thereby, cells with DNA damage will undergo mitotic catastrophe and apoptosis [73].

However, the most appealing therapeutic approach is by using methylation inhibitors. $14-3-3 \sigma$ is frequently silenced by $\mathrm{CpG}$ methylation in numerous types of cancer. Reversal of this hypermethylation can be achieved by administration of the metyltransferase inhibitor 5-aza-2deoxycytidine (5-Aza) and histone deacetylase inhibitors [74]. In vitro studies revealed that treatment of the cell lines with 5-Aza triggered the re-expression of 14-3-3 $\sigma$ in the cells, and 14-3-3 $\sigma$ mRNA expression level was increased in a dose-dependent manner. The sensitivity of cell lines to 5-Aza differed depending upon the cell types. In our recent work, the endometrial cell line (AN3CA) was more sensitive to the effects of 5-Aza in comparison to the prostate cancer cell line (LNCAP) [64]. Thus, methyltransferase inhibitors such as 5-Aza or others such as Zebularine and the recent histone deacetylase inhibitors could be of potential therapeutic use [75]. Clinical trials are underway, and they show promising results in patients with cancer.

14-3-3 $\sigma$ expression is lost in numerous carcinomas. This loss may lead to mitotic catastrophe and sensitize epithelial cells to DNA-damaging agents [76]. More recently, other $14-3-3 \varepsilon, \zeta, \gamma, \beta, \theta$ isoforms have been identified in cancer [77]. The $\varepsilon, \zeta, \gamma, \beta, \theta$ isoforms have been detected in lung cancer, suggesting that these proteins might be involved in lung carcinogenesis. In addition, reduction of 14-3-3 $\zeta$ expression impairs the G2 arrest which leads to mitotic catastrophe and increase radiosensitivity [78]. These data suggest that inhibition of 14-3-3 could be a useful approach in order to sensitize human lung cancers to ionizing radiation. The expression levels of $14-3-3 \zeta$ and 14-3-3 $\sigma$ in human tumors (biopsies or resection specimens) may be predictive of the effectiveness of subsequent radiotherapy for adjuvant treatment of cancer.

\section{CONCLUSION}

Although 14-3-3 proteins were first discovered in 1968, it was not until 10 years ago that research on 14-3-3 proteins gained special interest. This interest was spurred by the increased interest in methylation. Recent studies have made great progress towards elucidating the functions of 14-3-3 in cell cycle regulation, apoptosis, migration, and differentiation. In addition, proteomic has allowed us to better understand the interactions of 14-3-3 with other proteins (over 200). However, much yet is to be discovered. Epigenetic silencing of 14-3-3 $\sigma$ expression has been frequently found in numerous cancer types. Loss of 14-3$3 \sigma$ expression may contribute to carcinogenesis due to loss of regulation of multiple pathways. We predict that the future will hold promising answers to unlock the mystery of 14-3-3 involvement in cancer.

\section{ACKNOWLEDGMENT}

I like to thank Dr. Charles LeVea for his critical review of the manuscript, and Mr. Doug Nixon for his photographic experience.

\section{REFERENCES}

1 Das PM, Singal R. DNA methylation and cancer. J Clin Oncol 2004; 22:4632-42.

2 Gilbert J, Gore SD, Herman JG, Carducci MA. The clinical application of targeting cancer through histone acetylation and hypomethylation. Clin Cancer Res 2004; 10:4589-96.

3 Maruyama R, Toyooka S, Toyooka KO, et al. Aberrant promotor methylation profile of bladder cancer and its relationship to clinicopathological features. Cancer Res 2001; 61:8659-63.

4 Ferl RJ, Manak MS, Reyes MF. The 14-3-3 $\sigma$ reviews. Genome Biol 2002; 3: 3010.1-3010.7.

5 Moore BW, McGregor D. Chromatographic and electrophoretic fractionation of soluble proteins of brain and liver. J Biol Chem 1965; 240:1647-53.

6 Muslin AJ, Tanner JW, Allen PM, Shaw AS. Interaction of 14-33 with signaling proteins is mediated by the recognition of phosphoserine. Cell 1996;84:889-97.

7 Yaffe MB, Rittinger K, Volinia S, et al. The structural basis for 14-3-3: phosphopeptide binding specificity. Cell 1997; 91:96171.

8 Urschel S, Bassermann F, Bai RY, et al. Phosphorylation of Grb10 regulates its interaction with 14-3-3. J Biol Chem 2005; 18 (Epub ahead of print).

9 Rubio MP, Geraghty KM, Wong BH, et al. 14-3-3-affinity purification of over 200 human phosphoproteins reveals new links to regulation of cellular metabolism, proliferation, and trafficking. Biochem J 2004; 379:395-408.

10 Benzinger A, Muster N, Koch HB, Yates JR 3rd, Hermeking H. Targeted proteomic analysis of 14-3-3 $\sigma$, a p53 effector commonly silenced in cancer. Mol Cell Proteomics. 2005;18: [Epub ahead of print].

11 Jin J, Smith D, Stark C, et al. Proteomic, functional, and domainbased analysis of in vivo 14-3-3 binding proteins involved in cytoskeletal regulation and cellular organization. Current Biol 2004; 14:1436-50.

12 Fu H, Subramanian RR, Masters SC. 14-3-3 proteins: structure, function, regulation. Ann Rev Pharmacol Toxicol 200; 40:617-47

13 Seger R, Krebs EG. The MAPK signaling cascade. FASEB J 1995; 9:726-35.

14 Avruch J, Khokhlatchev A, Kyriakis JM, et al. Ras activation of the Raf kinase: tyrosine kinase recruitment of the MAP kinase 
cascade. Recent Prog Horm Res 2001; 56:127-55.

15 Dumaz N, Marais R. Protein kinase A blocks Raf-1 activity by stimulating 14-3-3 binding and blocking Raf-1 interaction with Ras. J Biol Chem 2003; 278: 29819-23.

16 Yaffe MB. How do 14-3-3 proteins work?-Gatekeeper phosphorylation and the molecular anvil hypothesis. FEBS letters 2002; 513:53-7.

17 Kato Y, Tapping RI, Huang S, et al. Bmk1/Erk5 is required for cell proliferation induced by epidermal growth factor. Nature 1998; 395:713-6.

18 Kato Y, Zhao M, Morikawa A, et al. Big mitogen-activated kinase regulates multiple members of the MEF2 protein family. J Biol Chem 2000; 275:18534-40.

19 Zheng Q, Yin G, Yan C, Cavet M, Berk BC. 14-3-3 $\beta$ binds to big mitogen-activated protein kinase1 (BMK1/ERK5) and regulates BMK1 function. J Biol Chem 2004; 279:8787-91.

20 Cheng M, Olivier P, Diehl JA, et al. The p21(Cip1) and p27 (Kip1) CDK "inhibitors" are essential activators of cyclin Ddependent kinases in murine fibroblasts. EMBO J 1999; 18: 1571-83.

21 Slingerland J, Pagano M. Regulation of the cdk inhibitor p27 and its deregulation in cancer. J Cell Physiol 2000; 183:10-7.

22 Sekimoto T, Fukumotot M, Yoneda Y. 14-3-3 suppresses the nuclear localization of threonine 157-phosphorylated p $27^{\mathrm{kip} 1}$. EMBO J 2004; 23:1934-42.

23 Crino PB, Henske EP. New developments in the neurobiology of the tuberous sclerosis complex. Neurology 1999; 53:1384-90.

24 Fujita N, Sato S, Katayama K, Tsuruo T. Akt-dependent phosphorylation of $\mathrm{p} 27$ promotes binding to 14-3-3 and cytoplasmic localization. J Biol Chem 2002; 277: 28706-13.

25 Hengstschlager M, Rosner M, Fountoulakis M, Lubec G. Biochem Biophys Res Commun 2003; 312:676-3.

26 Liu MY, Cai S, Espejo A, Bedford MT, Walker CL. 14-3-3 interacts with tumor suppressor tuberin at Akt phosphorylation site(s). Cancer Res 2002; 62:6475-80.

27 Li yong, Inoki K, Yeung R, Guan KL. Regulation of TSC2 by 14 3-3 binding. J Biol Chem 2002;277:44593-6.

28 Margolis SS, Korbluth S. When the checkpoints have gone. Insights into Cdc25 functional activation. Cell Cycle 2004; 3:425-8.

29 Forrest A, Gabrielli B. Cdc25B activity is regulated by 14-3-3. Oncogene 2001; 20:4393-401.

30 Dalal SN, Yaffe MB, DeCaprio JA. 14-3-3 family members act coordinately to regulate mitotic progression. Cell Cycle 2004; $\mathbf{3}$ : 672-7.

31 Melo J, Toczyski. A unified view of the DNA-damage checkpoint. Curr Opin Cell Biol 2002; 14:237-45.

32 Uchida S, Kuma A, Ohtsubo M, et al. Binding of 14-3-3 $\beta$ but not $14-3-3 \sigma$ controls the cytoplasmic localization of CDC25B: binding site preferences of 14-3-3 subtypes and the subcellular localization of CDC25B. J Cell Science 2004; 117:3011-20.

33 Lee J, Kumagai A, Dunphy WG. Positive regulation of Wee1 by Chk1 and 14-3-3 proteins. Mol Biol Cell 2001; 12:551-63.

34 Samuel T, Weber O, Rauch P, et al. The $\mathrm{G}_{2} / \mathrm{M}$ regulator $14-3-3 \sigma$ prevents apoptosis through sequestration of Bax. J Biol Chem 2001; 276:45201-6.

35 Nomura M, Shimizu S, Sugiyama T, et al. 14-3-3 interacts directly with and negatively regulates por-apoptotic Bax. J Biol Chem 2003; 278:2058-65.

36 Tan Y, Demeter MR, Ruan H, Comb MJ. BAD Ser-155 phosphorylation regulates $\mathrm{BAD} / \mathrm{Bcl}-\mathrm{XL}$ interaction and cell survival.
J Biol Chem 2000; 275:25865-9.

37 Cary LA, Han DC, Guan JL. Integrin-mediated signal transduction pathways. Histol Histopathol 1999; 14:1001-9.

38 Han DC, Shen TL, Miao H, wang B, Guan JL. EphB1 associates with Grb7 and regulates cell migration. J Biol Chem 2002; 277: 45655-61.

39 Rodriguez LG, Guan JL. 14-3-3 regulation of cell spreading and migration requires a functional amphipathic groove. J cell Physiol 2005; 202:285-94.

40 Honda H, Nakamoto T, Sakai R, Hirai H. p130 (Cas), an assembling molecule of actin filaments, promotes cell movement, cell migration, and cell spreading in fibroblasts. Biochem Biophys Res Commun 1999; 262:25-30.

41 Tombes RM, Faison MO, Turbeville JM. Organization and evolution of multifunctional $\mathrm{Ca}^{2+} / \mathrm{CaM}$-dependent protein kinase genes. Gene 2003; 322:17-31.

42 Davare MA, Saneyoshi T, Guire ES, Nygaard SC, Soderling TR. Inhibition of Calcium/calmodulin-dependent protein kinase kinase by protein 14-3-3. J Biol Chem 2004; 279:52191-9.

43 Nakajima T, Shimooka H, Weixa P, et al. Immunohistochemical demonstration of 14-3-3 $\sigma$ protein in normal human tissues and lung cancers, and the preponderance of its strong expression in epithelial cells of squamous cell lineage.Pathol Int 2003; 53:35360.

44 Lakin ND, Jackson SP. Regulation of p53 in response to DNA damage. Oncogene 1999; 18:7644-55.

45 Hermeking H, Lengauer C, Polyak K, et al. $14-3-3 \sigma$ is a p53regulated inhibitor of $\mathrm{G}_{2} / \mathrm{M}$ progression. Mol cell 1997; 1:3-11.

46 Taylor WR, Stark GR. Regulation of the $\mathrm{G}_{2} / \mathrm{M}$ transition by p53. Oncogene 2001; 20:1803-15.

47 Rodriguez M, Yu X, Chen J, Songyang Z. Phosphopeptide binding specificities of BRCA1 COOH-terminal (BRCT) domains. J Biol Chem 2003; 278:52914-8.

48 Chan TA, Hermeking H, Lengauer C, Kinzler KW, Vogelstein B. $14-3-3 \sigma$ is required to prevent mitotic catastrophe after DNA damage. Nature 1999; 401:616-20.

49 Yang A, Kaghad M, Wang Y, et al. P63, a p53 homolog at 3q2729 , encodes multiple products with transactivation, deathinducing, and dominant-negative activities. Mol Cell 1998; 2: 305-16.

50 Ghahary A, Marcoux Y, Karimi-Busheri F, et al. Differentiated keratinocyte-releasable stratifin (14-3-3 $\sigma$ ) stimulates MMP-1 expression in dermal fibroblasts. J Invest Dermatol 2005; 124: 170-7.

51 Urano T, Saito T, Tsukui T, et al. Efp Targets 14-3-3 $\sigma$ for protolysis and promotes breast tumor growth. Nature 2002; 417:871-5.

52 Lodygin D, Hermeking $\mathrm{H}$. The role of epigenetic inactivation of 14-3-3 $\sigma$ in human cancer. Cell Res 2005; 15:237-46.

53 Gasco M, Sullivan A, Repellin C, et al. Coincident inactivation of $14-3-3 \sigma$ and $p 16^{\mathrm{INK} 4 \mathrm{a}}$ is an early event in vulval squamous cell neoplasia. Oncogene 2002; 21:1876-81.

54 Umbricht CB, Evron E, Gabrielson E, et al. Hypermethylation of $14-3-3 \sigma$ (stratifin) is an early event in breast cancer. Oncogene 2001; 20:3348-53.

55 Cheng L, Pan CX, Zhang S, et al. Loss of $14-3-3 \sigma$ in prostate cancer and its precursors. Clin Cancer Res 2004; 10:3064-8.

56 Bhatia K, Siraj AK, Hussain A, Bu R, Gutierrez MI. The tumor suppressor gene $14-3-3 \sigma$ is commonly methylated in normal and malignant lymphoid cells. Cancer Epidemiol Biomarkers Prev 2003; 12:165-9. 


\section{4-3-3 proteins}

57 Ferguson AT, Evron E, Umbricht CB, et al. High frequency of hypermethylation at the $14-3-3 \sigma$ locus leads to gene silencing in breast cancer. Proc Natl Acad Sci USA 2000; 97:6049-54.

58 Lodygin D, Yazdi AS, Sander CA, Herzinger T, Hermeking H. Analysis of 14-3-3 $\sigma$ expression in hyperproliferative skin diseases reveals selective loss associated with CpG-methylation in basal cell carcinoma. Oncogene 2003; 22:5519-24.

59 Lodygin D, Diebold J, Hermeking H. Prostate cancer is characterized by epigenetic silencing of 14-3-3 $\sigma$ expression. Oncogene 2004; 23:9034-41.

60 Yatabe Y, Osada H, Tatemasu Y, Mitsudomi T, Takahashi T. Decreased expression of 14-3-3 $\sigma$ in neuroendocrine tumors is independent of origin and malignant potential. Oncogene 2002; 21:8310-9.

61 Moreira JM, Gromov P, Celis JE. Expression of the tumor suppressor protein $14-3-3 \sigma$ is down-regulated in invasive transitional cell carcinomas of the urinary bladder undergoing epithelial-to-mesenchymal transition. Mol Cell Proteomics 2004; 3 : 410-9.

62 Suzuki H, Itoh F, Toyota M, et al. Inactivation of the $14-3-3 \sigma$ gene is associated with 5' $\mathrm{CpG}$ island hypermethylation in human cancers. Cancer Res 200; 60:4353-7.

63 Iwata N, Yamamoto H, Sasaki S, et al. Frequent hypermethylation of $\mathrm{CpG}$ islands and loss of expression of the 14-3-3 $\sigma$ gene in human hepatocellular carcinoma. Oncogene 2000; 19:5298-302.

64 Mhawech P, Benz A, Cerato C, et al. Downregulation of the14$3-3 \sigma$ in ovary, prostate and endometrial carcinomas is associated with CpG island methylation. Mod Pathol 2005; 18:340-8.

65 Logsdon CD, Simeone DM, Binkley C, et al. Molecular profiling pf pancreatic adenocarcinoma and chronic pancreatitis identifies multiple genes differentially regulated in pancreatic cancer. Cancer Res 2003; 63:2649-57.

66 Osada H, Tatematsu Y, Yatabe Y, et al. Frequent and histological type-specific inactivation of 14-3-3 $\sigma$ in human lung cancers. Oncogene 2002; 21:2418-24.

67 Vercoutter-Edouart A-S, Lemoine J, Le Bourhis X, et al. Proteomic analysis reveals that $14-3-3 \mathrm{~s}$ is down-regulated in human breast cancer cells. Cancer Res 2001; 61:76-80.

68 Mhawech P, Greloz V, Assaly M, Herrmann F. Immunohistochemical expression of $14-3-3 \sigma$ protein in human urological and gynecological tumors using multi-tumor microarray analysis. Pathol Int 2005; 55:77-82.

69 Wilker EW, Grant RA, Artim SC, Yaffe MB. A structural basis for 14-3-3 $\sigma$ functional specificity. Am J Biochem 2005;25: [Epub ahead of print]

70 Benzinger A, Popowicz GM, Joy JK, et al. The crystal of the non-liganded 14-3-3 $\sigma$ protein: insights into determinants of isoform specific ligand binding and dimerization. Cell Res; 2005; 15: [Epub ahead of print].

71 Van Hermert MJ, Niemantsverdriet M, Schmidt T, Backendorf $\mathrm{C}$, Spaink HP. Isoform-specific differences in rapid nucleocytoplasmic shuttling cause distinct subcellular distributions of 14-3$3 \sigma$ and 14-3-3 $\zeta$. J Cell Sci 2003; 117:1411-20.

72 Kawabe T. G2 checkpoint abrogators as anticancer drugs. Mol Cancer Ther 2004; 3:513-9.

73 Hermeking H. The 14-3-3 cancer connection. Nature Rev 2003; 3:931-43.

74 Esteller M. DNA methylation and cancer therapy: new developments and expectations. Curr Opin Oncol 2005; 17:55-60.

75 Cheng JC, Weisenberger DJ, Gonzales FA, et al. Continuous Zebularine treatment effectively sustains demethylation in human bladder cancer cells. Mol Cell Biol 2004; 24:1270-8.

76 Dhar S, Squire JA, Hande MP, Wellinger RJ, Pandita TK. Inactivation of 14-3-3 $\sigma$ influences telomere behavior and ionizing radiation-induced chromosomal instability. Mol Cell Biol 2000; 20:7764-72.

77 Qi W, Liu X, Qiao D, Martinez JD. Isoform-specific expression of 14-3-3 proteins in human lung cancer tissues. Int J Cancer 2005; 113:359-63.

78 Qi W, Martinez JD. Reduction of 14-3-3 proteins correlates with increased sensitivity to killing of human lung cancer cells by ionizing radiation. Radiat Res 2003; 160:217-23. 